\title{
Most effective management style for modern workplace
}

\author{
F. ADIL NAMIQ \\ University of Debrecen, Faculty of Engineering, Department of Engineering Management, frya.adil@gmail.com.
}

Abstract. There are managers who are coaches, who are democratic, who are dictatorial and those who are consensus builders. All styles come with positives and negatives, many managers employ a combination of all to make progress. Ultimately, the managers that have the most successful teams are the ones who help each individual member of the team to grow. To manage the best way possible, you need to be strict but gentle and, employees will probably feel good and happy in a medium where inclusivity is a need. Balance in the work environment is imperative for empowering employees from all background to feel certain about their potential and accomplish their best. The higher the self-esteem, the more beneficial the employees are. People from different background can offer variety of abilities and experiences, aptitudes and encounters that might be of advantage to the organization and their work execution. Although some hybrid of aptitudes can be gainful with regards to helping each other, a mixture of skills and abilities among the group likewise implies that workers can gain from each other. By working nearby individuals of various backgrounds, experiences and working styles, creative ideas can be conceived then discussed among each other and offering feedback and proposals. Though one individual might be extraordinary at out of the box thoughts, another individual may have the important experience to execute it; so it is fundamental to play on every individual's skills, abilities and work together within the group.

\section{Introduction}

Simple definition of workplace would be "a place where people work, such as an office or factory" [1] every industry or organizations first aim is to benefit from their work and reach the purpose and targets they have built. One of the key drive is to have the right people for achieving that desired goals, workplace happiness and comfort have direct effect on achieving any organizations goals, you can take the best out of people by making them feel a pleasant working environment, secure and support from their higher managements within the a workplace, all these will result in increasing employees wellbeing and productivity. Keeping high morale in the workplace will give hard working employees in return. The idea of this research paper came from the diversity increasing over the last decade globally and throughout my experience within different multinational companies and working with different people in terms of nationality, culture, religion and background in which everyone have their own management style which made me think of finding a common ground among all those styles, so the aim of this paper is finding the most effective way of management which result in creating a better working environment that everyone would be happy and releasing the organization from one man's dependant management style. [2] 


\section{Modern workplace environment}

The place where people work for their employer is simply called workplace, a business environment, and the place might be a small home office or expansive office building or processing plant, depending on the size of the firm or organization. The working environment stands out to be one of the most significant social spaces for industrialized societies other than home, because of the significance of this place we need to analyse its properties and criteria in order to be managed as best as possible, in the below paragraphs we will explain four main characteristics or features of the modern workplace in which are different from classical or workplaces before the millennium change. The first characteristic is diversity which refers to the variety of differences between people in an organization. In which sounds simple, but diversity incorporated with race, gender, ethnic group, age, personality, cognitive style, tenure, organizational function, education, background and more. diversity is not just about balancing age brackets or the ratio of male/female within the workplace, everybody as an individual can bring distinctive things to the table, which is the reason diversity is so vital among a group. By procuring a diversity within a workplace the firm is more likely to go towards advancement and development because it bring variety of ideas with it, seeing the issues from different perspective which will result in continuous innovation and market growth, on the other hand if everyone thinks alike the creativity will die out and most likely you will see repeated approaches when it comes to production, marketing, sales and finacing.etc, working with this approaches might result in limiting growth and development which might cause the firm to collapse as the competition is very high.[3]

The second feature would be cultural changes that relate to the diversity of culture which is a type of valuing the differences in people, the contrasts can be founded on sex, age, ethnicity, and economic wellbeing. Organizations have understood the incentive in getting a various manpower, the present manpower is comprised of an extremely various populace of people from all around the world, which makes dynamic multiracial and multicultural associations. Such diversity carries with it numerous distinctions in aptitudes, capabilities, and experiences, this made a climate where diverse perspectives and thoughts are welcomed. [3]

The following feature would be technology in which we can say the advancement of technology is another challenge for the modern workplace. A thorough digital transformation strategy has therefore, become essential, today the new technology is enabling people for distance and remote working of their daily task which resulted in a flexible working hour in the office as people can control their tasks from anywhere, and, the lines between working hours and individual time have obscured, responsibilities and rolls change more often outdating the none maintained skills, organization structures are moving from the old model of complex practical chains of a command intended for productivity and viability to adaptable group-based models intended for speed, agility, and flexibility. [4]

And last but not least feature is generation gap that we can define it as the distinction of mental circumstance and absence of comprehension among youthful and old individuals is known as the generation gap and it is not easy to fill it up unless they spend time together and tries to acknowledge 
each other for whom they are. Generation gap can be seen in numerous terms identified with their talked dialect, fashion and clothing style, their own perspectives and ideas, respect, ethics and more. Education and professional life competition are tenser nowadays, which is another reason for generation gap, this makes individuals so self-associated that they don't have time for their friends and family and simply make themselves isolated from others. Innovation and advancement of technology in 21st century has been totally changed, in comparison with how it was in the nineteenth century and the quality of comprehension and snatching this new innovation is simpler for new generation in compare to older ones, the most ideal approach to expel this gap depends totally on individuals and their readiness to comprehend, relate and acknowledge each other with their own thoughts and preferences. [5]

\section{Management Styles}

Management style is best portrayed as a strategy of leadership that is utilized by supervisors. [6] Management is the technique of working with and via others to successfully acquire the goals of the organization, through efficient use of the available resources. [7] as management is a wide range subject and there are so many research's, publication and articles in this field, each one have different division and definition for the management styles used, during my research I came across so many articles dealing with this topic each have their own category of branching the styles but if we could summarize all the works done in this regard we will end up with seven styles which used mostly all over the world according to majority of the writers and authors.

At first, "Visionary or imaginative style" in which this style is most proper when an organization needs another heading. Its objective likely moves individuals towards a new set of shared visions and goals. Visionary leader focuses on where a group is going and doesn't matter how it gets there in other words the focus is on the destination, not the road, allowing individuals to advance, explore and take risks. [8]

Secondly, "Coaching style" in which this one-on-one style centres on creating people, showing them how to improve their performance and aligning their goals with organization goals.[8] coaching style works best with employees who demonstrate activity and need more expert advancement. [9] However, backfire is expected if it goes towards "micromanaging" which will cause losing selfconfidence and morale for the employee. [8]

The third style is known as an "Affiliative style" which underlines the significance of collaboration and makes group harmony by strengthening peoples communication. It is specifically important when you have to enhance the balance of the team, improve morale, and restore the broken trust and communications in the organization. [8] However, it has its downsides, continuous positive feedback on the group performance might lead to poor performance to go uncorrected and persuade that insignificance will be endured. [10]

Another approach is a "Democratic style" A democratic manager is a person who solves issues or makes changes with the aid of asking crew members for their feedback, recommendations, and ideas. This leader can be uncomfortable with making all of the decisions themselves. [10] This approach can 
be catastrophic during crises, and in the times that quick and urgent decisions are needed, also it's time consuming and decision making process takes longer time. [11]

Furthermore, there is "Pacesetting style" where the leader sets high standards for performance. He or she is obsessive about doing things better and faster and asks the same from everyone, this style destroys work environment, employees will experience overwhelmed by managers needs for excellence. Working guidelines might be clear for the manager, however, they do not clarify them properly and expects people to know what to do and how to thinks, it will lead to morale drop and failure feeling among people. [12] But it has shrouded advantage: quick acquiring of the outcomes within the short time period, there will be a high-energy group with the terrific performance in terms of conducting tasks as well as the quality of the work itself. [13]

"Autocratic style" this is the style where the manager tells the employees what to do. Consequences awaits them if they fail to fall in line, employees are inspired generally via fear of discipline. The company has precise, clear regulations that employees should comply with. The higher management have no interest in hearing feedbacks from the employees. [14] All things considered, in emergency circumstances, when urgent action is required, it can be a successful approach. [15]

Finally, there is "Laissez-faire style" that is the inverse of autocratic, workers are permitted to settle most of the decisions, with management giving direction when required, the manager for this situation is viewed as an adviser instead of a leader. This style of management is mainstream in new businesses and technology organizations, where the risk taking is supported. [15] It works well when a group of experts are working together and they have the success skills to achieve the desired goals. [16]

Note that what recognizes every initiative style above isn't the individual attributes of the leader, yet rather the nature and requirements of the individuals who are being driven.

\section{Role of managers}

Managers arrange and regulate the work by other individuals with the goal that authoritative objectives can be refined, none managerial employee work specifically on a job or assignment and have nobody answering to them which is the feature differentiate managers from their employees yet the main purpose of manager is making sure that the works and activities are completed in the best way and as efficient as possible. Organizations have three qualities in general; a purpose, made from individuals, and a conscientious structure. A considerable number of the present organization are organized to be more open, adaptable, and receptive to changes, managers are critical to the firms, companies or organization for three reasons. To begin with, organizations require their managerial aptitudes and abilities in unclear, complex, and disordered circumstances. Second, managers are basic to complete things and finalizing the tasks and finally, managers can affect employees efficiency and reliability; the way workers are overseen can influence the organizations budgetary execution, managerial potentials has been appeared to be essential in making hierarchical esteem. [17]

Managers should have the ability to perceive and use the qualities of individual workers to properly pick up on their strength and weakness and utilize those special qualities in a way that is helpful to the 
organization. No two workers are the same and people can be significantly more compelling when their skills are utilized further towards their advantage. [18]

Another tool for a good manger is the ability to change management styles for depending on whom they are responsible for, the best manager perceive that employees do not react the same to the way he/she manages, however, they can alter their management style as needs be to amplify workplace satisfaction and, thus, increasing efficiency. For instance, some workers respond better to harsh and criticism and under pressure working while others are better responding to gentle, encouraging guidance. [18]

\section{The Importance of management}

In case you are designer or engineer or finance officer or any field other than management, you may not see how contemplating management will help you in your mission and you might ask why management is important? Management is about unifying the group works and performance then directing them towards the organizations goal and objectives. It is the key element to forecast, plan, execute, coordination and control over operations. [19]

Proper management brings several benefits for the firm, first helps in achieving the organization goals through production arrangements and directing everyone's focus on achieving the desired goals and targets. Second is utilizing the resources in the best way possible which includes both human resources and products, taking the best out of people and minimizing the waste. Another benefit is reducing and controlling cost using proper planning to minimize inputs and maximize the outputs. Management also gives a sound organization by which the responsibility and accountability is clear and everyone knows what they have to do, appointing the right person to the right place. Management also helps organization to adapt the changes in the market and what are needed for continues growth and survival of the firm. Also helps achieving a better economy which result in society wealth increment. Proper management simplify all difficulties by waste reduction and good planning to advance the living standards. It expands the benefit which is useful to business and society by achieving maximum outputs at the least cost through creating work openings that produce income. [20]

\section{Research}

During the working on the paper I made a survey among people in different position, culturally, nationality, age and gender on some questions that I think they are important to be considered within a workplace to achieve a better understanding between employees and managements. 100 persons were targeted to participate in the survey in which all of them are multinational company's employee for instance (Managers in different companies for example MOL-group, Taqa for oil and gas, GE etc.) also engineers, finance officer, HR, supply chain managers with different years of experience. Selecting these people for the survey come from their different working style and their way of daily works management depending on their work environment, their review will result in a collection of diverse point of view and approaches. for example a mid-level manager have its own criteria as they are the 
link between the higher managements and the workforce, to manage this life style they need to have proper skills to practice their daily work at the best way possible, all the targeted audience have a unique role and responsible which makes their experience and insights important to be considered for my survey. To build the survey I asked and consulate my former colleagues, brainstorming meetings, also discussed the subjects with some experienced managers on Quora website, after all these thoughts exchange sessions I came up with a list of question for the survey and build it on Survey Monkey website then distributed the link, After finishing the survey I collected all the data and applied simple correlation method on them, blew plots will preview the survey results alongside with my analysis and explanations.

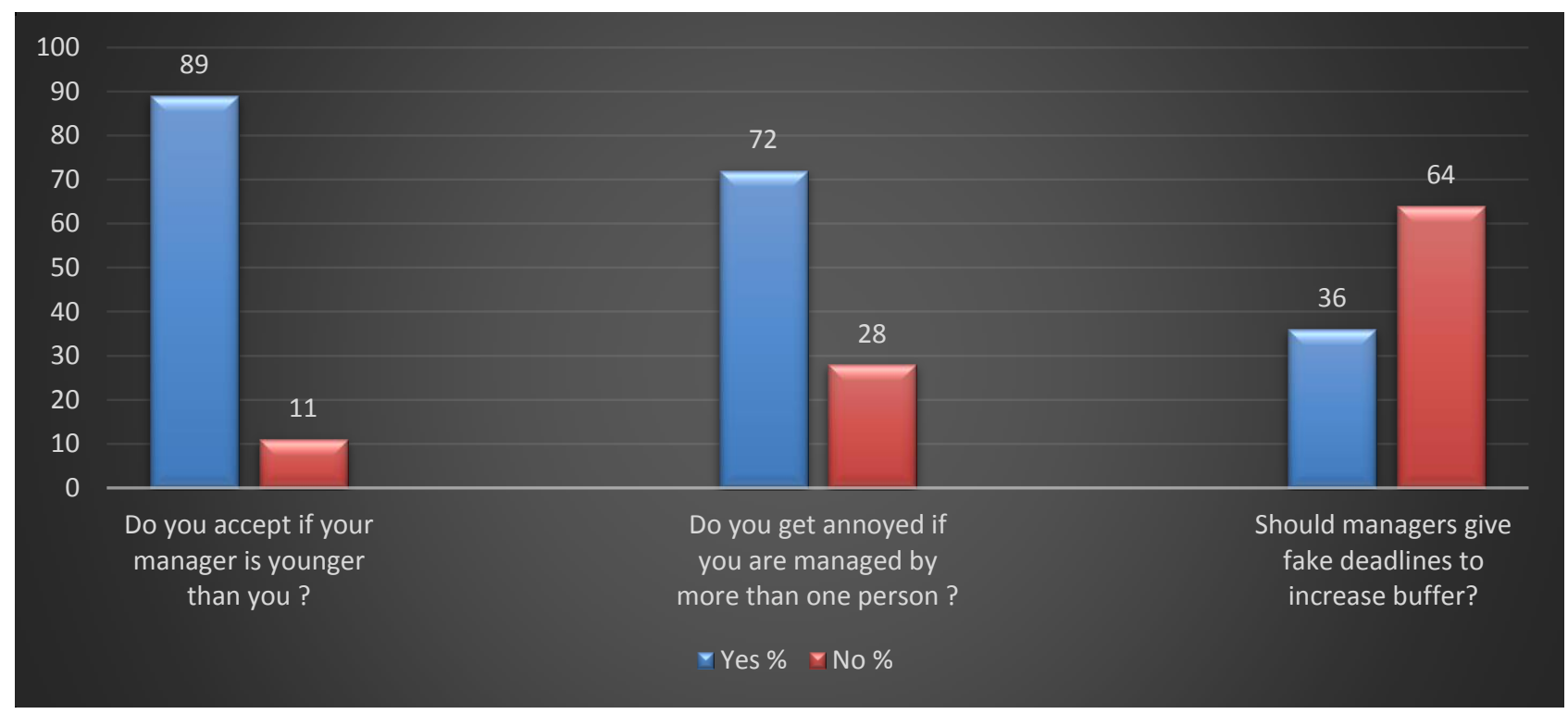

Figure 1: managers and management [22]

From the Figure 1 we can see that being managed by a younger person is acceptable by majority of people (89\% said Yes and $11 \%$ No) to the younger manager within the firm, age is just a number as long as they competent and fully qualified to hold the responsibility and have the skills required to manage a group of people who are different in term of age, background, religion, nationality gender. Etc. another concern is been supervised by more than one person which can be confusing and irritating at the same time which why most people don't like such environment to work in, according to Figure 1 (72\% said they get annoyed when managed by multiple bosses while $28 \%$ said they have no problem with it and it has no effect on them). Having more than one boss might lead to overburden. one of the most serious outcome of having more than one individual allotting you work, is basically having excessive work to do, The more supervisors you have the more clashing messages you get, now and then this occurs out of obliviousness - your managers aren't mindful of what the others are stating - or on the grounds that individuals are pushing their own motivation. Regarding fake deadlines sometimes superiors are giving fake deadlines just to put extra pressure and increase buffer in the workplace which is unlikable by most people according to the survey as the responses are $36 \%$ said yes they agree with that idea and $64 \%$ of the audience said No to fake deadlines) but in my personal opinion, I find it necessary sometimes for certain situations. [21] 


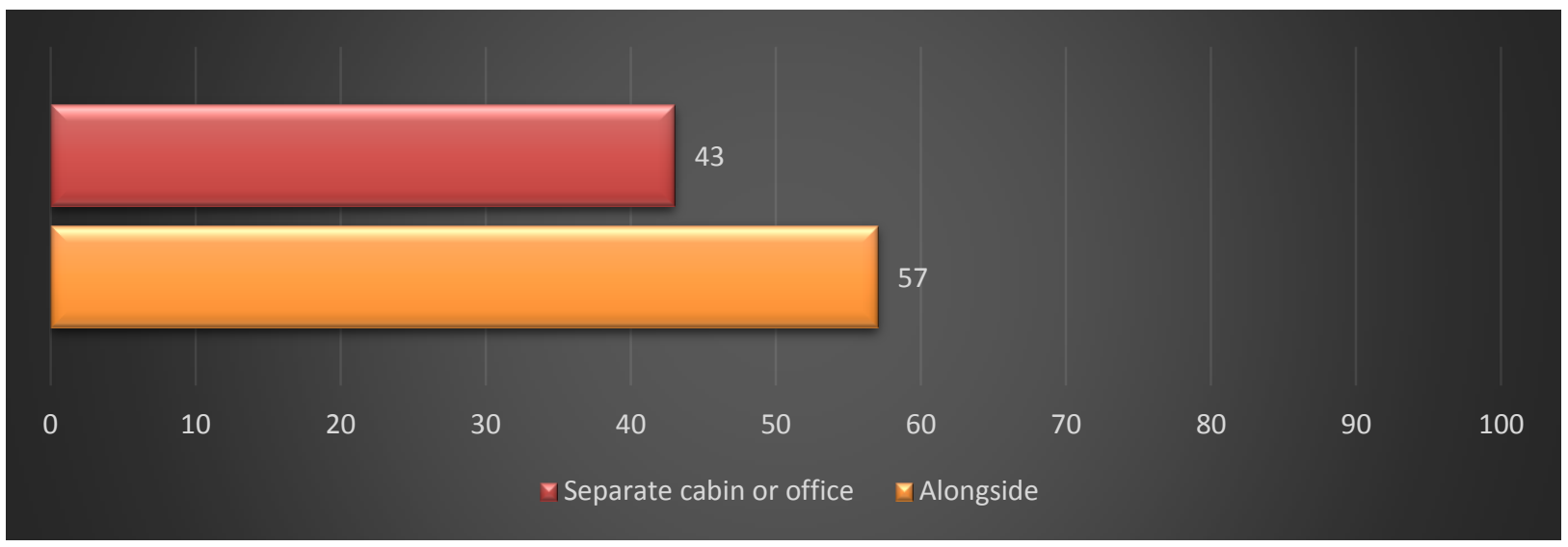

Figure 2: Working environment [22]

Another concern is working environment in terms of preference of working alongside your manager or separately in an enclosed cabin or office? as the manager or superior working place also have direct effect on the employee's performance, according to the (Figure 2) both are accepted as the responses are very close $(43 \%$ prefers separate cabin or office and $57 \%$ prefers working alongside their managers or staff) but in personal point of view the new generation prefers working alongside each other which gives more motivation to works and less distraction.



Figure 3: Timing preference [22]

Also the timing of the work is something to consider for the modern workplace which can be summarized in the preference of Task based work or hrs-based work. The classic working style is hour based for example eight hours of work a day but the new trend is task based working style which is preferred by majority of people as we can see from the (Figure 3), the responses are (75\% to $25 \%)$ in favour of task based style, this style states that an employee have certain amount of tasks within a day or a period of time that to be completed and some companies are following that style now and they achieved great performance from their employees. In my opinion this style decrease time waste as people are doing their best in order to finish their work and leave to do other life duties. 


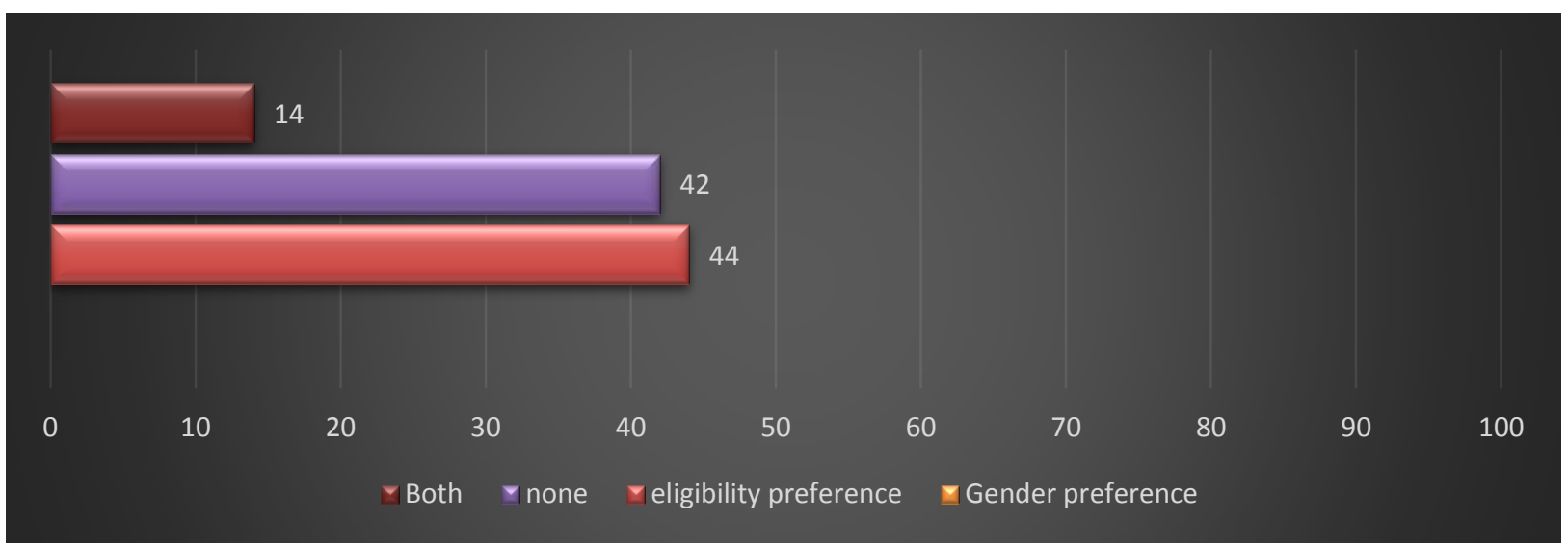

Figure 4: Promotion or recruitment preferences [22]

Finally, regarding responsibility, recruitment or promotion or how should we appoint someone that fits the position, should we be more careful of gender balance within the organization, according to the (Figure 4) majority of people are against gender preference as there is zero response for it, eligibility and no preference are close to each other (44\% and $42 \%)$ accordingly while (14\% of the audience) likes both eligibility and gender preference to be considered together, they want someone whose fit for the position regardless of their gender or no preference at all which also comes back to eligibility of the appointed person.

\section{Conclusion}

Choosing one style of management might be impossible as all of them have advantages and disadvantages, any of them is best for certain situation but if I have to choose one style, then I will say situational or adaptive leadership works best in most cases, you will get more from your people if you are stern but understanding, keeping an open-door policy, asking for feedbacks, and keeping all informed on what is going on inside the company or organization. Most people prefer managers who are good communicators and friendly, people tend to be recognized and respected, engaging your employees in daily activity will result in moving towards a continuous improvement, the productivity will increase, quality will enhance, turnover ratio will decrease, and it will cause in reducing absence from work, considering all above parameters you will see happiness within the organization, people will work with passion and loyalty as they feel recognized and respected which in return the profitability of the organization will be more and more.

Managers should have a clear vision about the goals to be achieved and have passion for the organization along with the ability to inspire trust among the employees as well as making sure that everyone believes in the organization visions and they are excited about it.

\section{Summary}

Current workplace requires different managing skills as the diversity increases, the new generation workforce needs more attention due to mixture of different culture, religion and background, people are reaching high position at young ages which is acceptable as long as they eligible to hold that 
responsibility, two different generation can be noticed nowadays in which the first one is having years of experience but sometimes they lack of technology skills or communication with new generation which are very hard to manage, they are more demanding they expect high salaries with least experience, more free time and distance working, following the applied organizations policies is not their point of strength as they tend to change things, suggesting new ideas and expecting to be implemented quickly which is the main conflict between the two generation.

Not to forget the role of female workers have increased during the last decade, now women are given more chances and competing with mans in a very high level, anyone can reach any position based on eligibility which is accepted by majority of people regardless of age, religion, nationality, gender. Etc.

Some concerns to be considered that I have seen personally is the preferences based on cultural or linguistic background that will result in un-unified workforce, the organization will turn into a bunch of groups in which all works on their own groups interest. I believe all organization should have a strict policies against any type of preferences and insist on unified language within the workplace.

Also religion have a strong impact on religious people behaviour and efficiency, so it should be respected and well treated. the organization should consider this subject carefully because it's like double-edged sword as if you praise it and respect people's belief the productivity will increase, the harmony and happiness of the workplace will grow in return and in the other hand the organization might face problems even operating in the area.

\section{References}

[1] Oxford dictionaries.

[2] http://www.businessdictionary.com.

[3] Cultural diversity in the workplace by George Henderson g. (2001).

[4] Ben Rossi, Technology is ready to define the future of the workplace. http://www.information-age.com/technology-ready-define-future-workplace

[5] Essays on generation gap on "www.teachingbanyan.com" website.

[6] Google dictionary

[7] www.managementstudyguide.com

[8] Alan Murray, Wall Street journal, six most used management styles. https://www.wsj.com/articles/SB10001424052748704041504575045163417674970

[9] Joe Neely, 6 Types of Management Styles for effective leadership, https://toggl.com/blog/management-styles/

[10] 5 Leadership Styles: By Angus Gill, http://www.saxonsgroup.com.au/blog/leadership/5-leadership-styles-pros-and-cons/

[11] https://connectusfund.org/8-advantages-and-disadvantages-of-democratic-leadership-style

[12] http://www.danielgoleman.info/daniel-goleman-use-the-pacesetting-leadership-stylesparingly-2/

[13] https://www.money-zine.com/career-development/leadership-skill/pacesetting-leadership/ 
[14] Chris Rhatigan, An in-depth look at six different management styles. https://www.tinypulse.com/blog/six-management-styles

[15] 6 Types of Management Styles, https://online.grace.edu/news/business/types-of-management-styles/

[16] What Is Laissez-Faire Leadership? By Kendra Cherry, https://www.verywellmind.com/what-is-laissez-faire-leadership-2795316

[17] Management, 11th edition by Stephen p Robbins and Mary coulter.

[18] J. Spilker What Makes a Good Manager? 17 Business Leaders Share Their Best Tips https://www.workzone.com/blog/good-manager/.

[19] K, Leonard, Four Functions of Management and Leadership Styles, http://smallbusiness.chron.com/four-functions-management-leadership-styles-64958.html

[20] https://www.managementstudyguide.com

[21] A. Gallo, Managing multiple bossed, https://www.hbr.org

[22] Own research 